Lunt, P. (2008) Little Angels: The mediation of parenting. Continuum: Journal of Media \& Cultural Studies, Vol. 22, No. 4, August 2008, 537-546.

Little Angels: the mediation of parenting.

\title{
Peter Lunt
}

School of Social Sciences

Brunel University, UK.

\begin{abstract}
This paper analyses a make over TV programme called Little Angels in which a psychologist offers advice to parents of young children. The conduct of the children, the intervention of the psychologist and the consequent attempts by the parents to influence their children's behaviour through changing their parenting style are all filmed in the family home which has been saturated with cameras. A variety of features of the programme are identified: the use of surveillance technology, the deployment of psychological discourse, the role of therapeutic intervention, the use of narrative to tell the story of transformation. This analysis is set against governmentality theory and reflexive modernity theory; both provide partial insight into the way the programme is produced and the broader social significance of such representations of everyday life.
\end{abstract}




\section{Individualization and Therapy Culture}

There has recently been a renewed interest in the question of individualization in sociological analysis of modern societies (Beck and Beck-Gernsheim, 2002; Giddens, 1991; Rose, 1989). Although the relative autonomy of the individual is a long standing feature of modernity nurtured both by the shift from tradition to enlightenment and the increasingly secular, urban, industrial character of modern life the feeling is that there has been a significant shift in individualization. New ways of governing that shift the emphasis from sovereign rule to a partnership between relatively autonomous individuals and social institutions, the change in the management of risk and welfare from the collective to the individual level, the move from liberal to neo-liberal economies and the relative importance of consumerism to identity (Lunt and Livingstone, 1992) all point to the increasing salience of individuals. Social institutions increasingly address the public as individuals with rights and needs rather than social collectives and, arguably, individuals' sense of themselves is less defined in terms of traditional social roles and origins and more in terms of their personal identity (Giddens, 1991).

Furedi (2004) suggests that contemporary society is marked by an increased focus on the internal life, the psychology, of the individual and an increased focus on psychological solutions to social problems. We would expect such social changes to be reflected in culture and to document this Furedi (2004) maps the rise of psychological terms such as 'self-esteem', 'trauma', 'stress', 'syndrome', and 'counselling' in the British press since the mid 1990s. Before the mid 1990s such terms were rarely used; the term 'self-esteem', for example, rarely appeared in press coverage from 1980 to 1986, slowly rose in use to around 500 occurrences by 1995 and rapidly escalated to over 3000 mentions by 1999. Furedi interprets this increasing circulation of psychological terms in public discourse as reflecting the growth of 'therapy culture' in which individuals increasingly focus on their own vulnerability and at the same time demand that social institutions respond to their psychological needs through the provision of public information and services. For Furedi (2004), therapy culture is two sided since it both increases the focus on internal psychological processes and a sense of autonomy but is also linked to a culture of litigation and complaint and anxiety about the self.

The themes of individualisation and the turn to the psychological have been taken up in the analysis of popular culture in response to the proliferation of 
programmes that enrol the public as participants on popular TV shows increasing the mediated visibility of the public. One example is the confessional and therapeutic character of talk shows and reality TV (Livingstone and Lunt, 1994; Grindstaff, 1997; Gamson, 1998; Dovey, 2000; Illouz, 2003; Hill, 2005). Another is the development of lifestyle TV such as cooking and gardening programmes which shifted into prime time slots in the UK during the 1990s (Bell and Hollows, 2005; Brunsdon, 2003). Brunsdon (2003) interprets the rise of lifestyle programmes against three broad social changes: increasing home ownership, the increasing numbers of women in the workforce and the increase in the age of child bearing. Together these factors have created a new consumer group of single and childless couple households focused on home ownership, personal and career development and leisure, creating a market for programmes that link identity to consumerism. Such programmes provide an important site for the expression of taste and expertise that responds to the emerging needs of lifestyle consumption. A key element of this focus on lifestyle is the dynamic of transformation (Moseley, 2000; Brunsdon, 2003) and the programmes provide advice that is sometimes technical (this is how to rag - roll, when do I prune my apple trees), and that sometimes offers guidance on taste (what counts as quality and value in the transformation of the domestic sphere and the self) (Philips, 2005)? An important feature of all these programmes, noted by the commentators above is the significant role of 'expert hosts'; indeed accompanying the proliferation of the public on popular TV has been an equal proliferation of expertise (Taylor, 2002; Lewis, 2008). Experts of every description now appear on our screens to offer analysis, advice and criticism to individuals concerned to improve themselves (gardeners, interior designers, fashion gurus, a variety of life coaches and therapists).

All these programmes extend the visible public, taking aspects of the private sphere and placing them in a context of public scrutiny. The presence of the public has been a feature of television since its early days but the role that the public plays has changed over time (Livingstone and Lunt, 1994). The public presence at televised large scale public events including sports events and ritual pubic occasions is critical to the sense of liveness that creates a feeling of co-presence for the audience at home. In game shows, the audience are in a different role as they become the main protagonists of the show, appearing 'on stage', their fortunes on the programmes and their reactions are central to programme structure and content (Lunt and Stenner, 2005). These programmes are a staged adaptation of an earlier tradition in which 
Candid Camera simultaneously placed the public at the centre of the programme whilst ironically distancing them through ironization. These examples, however, were early indications of a trend that has developed rapidly in recent years with the advent of talk shows, reality TV and make over TV. In these genres, interactions between members of the public are the core of the content and structure of the programmes. Instead of the public revealing themselves in the interstices of a game show or as a mass at a sporting event, these genres put them centre stage and focus on them - on their inner turmoil and their emotional reactions as they live together in a reality TV show, or are filmed as they prepare for their weddings, or swap houses or jobs to try a different way of living or working or are coaxed to open up, reveal and confront difficult personal feelings and relationships.

This therapeutic dimension of the proliferation of the visibility of the public has lead to considerable critical scrutiny and there are two competing sociological explanations for these developments. Governmentality theory (Barry et al 1996, Dean, 1999), inspired by Foucault's writings on the constitution of modern modes of subjectivity, offers an analysis of the enrolment of subjects to institutional discipline through the internalisation of normative discourses of the psychological combined with public acts of confession. Under this view the modern subject comes into being through a combination of self-reflection, internalizing institutionally mediated norms of conduct in a society that is understood as a loosely connected network of institutions oriented to the governance at a distance. In contrast, reflexive modernity theory suggests that increasing institutional individualization (rather than 'discipline') creates a set of social conditions in which the individual is thrown back on their own resources to manage their identities. This theory offers a different view of the relationship between individuals and society to that of governmentality theory. Under reflexive modernity social institutions establish a set of conditions under which the individual becomes the basic social unit addressed by the state and commercial institutions. The individual then becomes a consumer of goods and services provided by commerce and by public institutions operating as institutional civil society in which resources are made available to the reflexive subject through the provision of advice and information.

These two theories offer different possible interpretations of the proliferation of mediated representations of the psychological life of individuals. Under the governmentality view such programmes are constitutive of a new mode of 
subjectivity in which governance operates through the dispersal of techniques of the self through which individuals manage and control their own conduct (Palmer, 2003; Ouellette and Hay, 2008). Under the reflexive modernity interpretation such programmes reflect the way that the relationship between individuals and social institutions are marked by a number of important transitions. The mode of address (and administrative practice) of social institutions has shifted from the collective to the individual, so that the public are increasingly understood, analysed and addressed as individuals rather than members of social groups. The programmes also reflect the situation in which the life chances of individuals are less marked by the chances given to them by birth, with the individual portrayed as having the possibility of constructing different life trajectories which require them to develop selfconsciousness related to constructing their life narrative. These shifts in turn relate to the changing nature of personal relationships in which traditional conceptions of role and duty are less salient and instead the co-construction of relatively socially detached forms of social relationships which are open to scrutiny, review and renewal becomes the norm.

\section{Parenting and Childhood}

Recent work in the sociology of childhood (James, Jenks and Prout, 1998) has argued that the general proliferation of discourses of the self in late modern society extends to both parents and children. Traditionally the family was studied as a central informal social institution that functioned to socialize children into the norms of the family and society (Parsons, 1951). This view of the family has been increasingly challenged and the black box of the family has been opened up to reveal the complexities of interaction between parents and children (James et al., 1998).

The picture emerges of children as agents in the family in their own right, and as worthy of rights in relation to the broader society but also there has developed in parallel an increasing focus on and awareness of the child as victim, or the vulnerable child. The modern family appears as both increasingly democratic in acknowledging the autonomy and needs of children but nevertheless parents still control and threaten children. Consequently although the focus of concern might be children, the locus of policy initiatives is commonly the parent(s). Ironically, also, although the child has been discovered as a sociological subject in recent years, contributing to the closer scrutiny of childhood in the family, school and locale, an older conception of the child, one that James et al, (1998) call 'presociological' still provides the means of 
intervention through therapeutic intervention or advice to parents on parenting. How might the broader framework of individualization versus governmentality apply to an analysis of the social dimensions of the rise of therapy as a major discourse of our age? Is therapeutic culture best thought of as an institutional support for the reflexive subject (the parents dealing with their children through reflection and communication aided by advice) or is it part of a new, subtle form of social control whereby the parents both internalize a conception of the child as problem or vulnerable and add insult to injury by adopting a therapeutic frame to 'deal with' their child's 'problems' all in the apparently benign name of therapy (Furedi, 2004).

In this paper we focus on an example of make over programming that explicitly addresses a social issue (concerns about the capacity of parents to bring up their children) as a psychological problem (the problematic behaviour of children). The programme offers 'positive psychology' as a response to the experience of parents living in contemporary society, experiencing the professionalization yet isolation of parenting, moral panics about children being raised outside traditional family structures and the increasing focus on the idea that the provision of life skills and rapid therapeutic intervention is a positive tactical response for a mediated public service. The programme we are focussing on is Little Angels, a make over programme in which a psychologist provides instruction in parenting skills to families with young children. We will discuss an example of the programme in some detail against the background of the arguments above concerning therapy culture, discursive social control through expert mediation and subjective internalization of therapeutic discourse.

\section{Little Angels}

Little Angels is here treated as a case study in the mediation of therapy culture. Little Angels is a series (there have been 3 series so far) appearing first on BBC3 (the $\mathrm{BBC}$ 's digital channel) and then repeated on $\mathrm{BBC} 1$. The programme runs for half an hour and the basic proposition revolves around parents who are having problems managing their young children (aged 3-5). Each episode documents the intervention of clinical psychologists into the family's life with the aim of dealing with a variety of everyday parenting issues; temper tantrums, violent or aggressive behaviour, 'naughtiness' and problems getting children to sleep. On the BBC website 'Little Angels' is positioned as part of factual broadcasting on the theme of 'parenting' 
alongside a documentary series on child development called Child of Our Time. The website itself also offers a range of advice for parents. The programme is interestingly positioned in genre terms because it has arisen in the 2000s as part of the emerging make over format showing the cross over of reality TV into programmes that have an explicitly public service remit achieved by broadening the range of factual broadcasting (Hill, 2007).

\section{The Programme}

Little Angels fits the before and after transformational format of makeover TV, starting with the disruption of the home by children behaving badly and the story of the parents' attempts to bring harmony and order to the household by changing their approach to parenting. A variety of material is presented: live shot material in the homes of the participants filmed on cameras spread around the house; interviews with the adult participants; interactions between the parents and the psychologist and a narrative voice-over.

The home audience are introduced to the family through a combination of live shot material of children and parents in conflict and initial interviews with the parents saying what their problems are along with a voice over commentary. The narrator tells the audience that these are "working parents who only have evenings and weekends to be with their kids" (series 1 episode 1) and that the parents are in "a constant struggle" as images of familial conflict play out on the screen. The narrator tells us that there have been no complaints about the children's behaviour from school or nursery "but the boys leave Jo and Jason permanently exhausted" (series 1 episode 1). In a talking head shot, the mother then elaborates the problems as she sees them - the boys squabbling, fighting, screaming (not a 'fun time'). A series of vignettes selected from live shot material are then introduced to illustrate the points made by the mother children being wilfully disobedient, fighting, bullying, throwing a tantrum in a shop, refusing to go to bed. In a final talking head of the parents they lay out what they would like to achieve in relation to their children's behaviour. The desires of the parents are presented as modest: "some time in the evening", "just peace and quite".

These examples illustrate well the idea of a social issue presented as a psychological problem as the narration moves from an account of the changing nature of work (dual career families and the increasing commitments required of workers) taking in the broader social problem of family breakdown and growing ill discipline 
amongst children and the changing nature of family life in contemporary society before introducing the idea that psychological intervention might provide an answer to parents' problems. Several themes are articulated in the show's opening title shots: the use of live shot material as a document of the state of relations in the household, the central role of psychological expertise in the programme and that the overall story as a transformation narrative emphasizing the effectiveness of therapeutic intervention?.

\section{Meet the Expert}

Following the opening titles, the scene switches, and to a background of upbeat music the narrator announces that "The Bartons have called for some help" over the scene of the expert driving towards the family home. She is introduced as "Clinical psychologist Dr Tonia Byron [who] works with lots of families, teaching them how to manage their kids behaviour" (Series 1 episode 1). She is a prototypical young professional, neatly dressed, made up and wearing sun glasses as she drives her neat small car. Her aim is presented as going to 'try to help' the parents deal with their children.

\section{Meet the equipment}

In the next section of the programme the set up of recording equipment in the home is introduced - the family have agreed to be 'filmed over the summer' and the cameras are shown being fitted into the home "to capture behaviour as it happens". This scene ends with the meeting of the expert and lay participants in a performed 'as live' sequence, the psychologist is seen walking up the path of the family home being greeted and invited in by the adults. The combination of the deployment of psychological expertise and the saturation of the house with cameras in surveillance mode are key features of the programme (Andrejevic, 2004). This combination fits well with contemporary notions of governance - that a social problem can be managed by encouraging the internalization of techniques for behavioural control and the use of surveillance technology that creates a sense of scrutiny which leads the individual to reflect on their own behaviour. Alternatively, we can read the programme as acknowledging the pressures on couples who are attempting to live out relationships of equality in relationship to their careers and sharing parenting. The 
role of the psychologist is to provide a resource through which the parents can reflect upon and adjust to the problems resulting from their pressured lives.

\section{Making over behaviour}

There then follows a scene that is central to the programme and which raises a range of questions about the ethics of the show. The psychologist has brought video extracts from the filming that has taken place over the previous weeks and she now goes through these extracts with the parents. Examples of particularly problematic behaviour of parents and children are identified. The psychologist offers an analysis examining the link between the parents' behaviour and that of the children with a particular focus emerging on the conduct of the parents. This is an important emphasis - whilst the children and their behaviour is presented as what clinical psychologists term the 'presenting' problem, the psychologist works directly only with the adults in all phases of the programme, focusing on their conduct as parents, making suggestions about the way that behaviour that they see as problematic or bad in their children is either a response to or can be ameliorated by a change in the way they act towards the child.

This scene is a critical moment in the narrative of the programme. On one level the review of live shot material lead by the psychologist can be seen as a version of the 'before' of the magazine make over but here the before is not simply a photograph of clothes or appearance but a reflective viewing of edited highlights of difficulties between parents and children with commentary by a child psychologist. This is also a critical moment of the programme in the sense that the psychologist offers a vocabulary to the parents as a way of thinking about the relationship between their conduct and their child's behaviour. At the same time an ethic is introduced to the parents which has two dimensions; it is an ethic of reflection exemplified by the psychologist's reflections on the video material but also a practical ethics of parental conduct offered in the form of rules of thumb for behaviour loosely informed by psychological theory

Here the double meaning in the title of the programme is revealed; the ironic meaning of 'little angels' contrasts with the images of the children being 'difficult' at the beginning of the programme and anticipates what the programme tries to achieve through intervening so as to transform the little devils into little angels. But it also reflects the underlying theory revealed in the focus on the conduct of the parents that 
children are, in principle, all 'little angels' - inherently good, positive and just waiting for the opportunity that good parenting brings to reveal their positive qualities.

To illustrate the subtle use of psychological discourse to establish norms and the focus on the parents reflecting on their own behaviour consider the following extract from the first Little Angels programme:

"Now, one of the biggest mistakes we make as parents, and we all do it, is we leave them alone when they're behaving nicely and say nothing to them, and when the behaviour gets kind of out of control we come in all guns blazing and they get tons of our time and tons of our attention. Now, if we do that often enough, what they learn is, the way to more of mummy or the way to get more of daddy is to start beating each other up because actually there's no payoff, there's no reward for sitting and playing nicely."

Three more incidents are reflected on in a similar way and discussed, with the narrator summing up thus/as follows?: "So if they want to fix their kids behaviour it looks like Jo and Jason will have to change their own"

The video analysis complete, the psychologist then meets with the parents in the garden to debrief them and plan a new parenting strategy. This is another critical phase of the programme because after the surveillance and critical reflection the next phase of the programme involves the formulation of a new parenting ethic that is suggested by the psychologist as a way forward:

"We're gonna set clear limits and clear boundaries around behaviour and you're going to be lavishing praise on your boys at every opportunity you can when they are doing all the wonderful things you want them to do and when they do the things you don't want them to do you're going to we're going to have two separate ways of managing the two older boys."

In addition to the use of their own conduct as a way of conditioning the behaviour of their children other techniques for managing their children's behaviour are introduced 
including the use of a sticker chart for rewarding and punishing behaviour and the use of a 'time out' procedure for the other, younger child.

In governance terms at this stage of the programme the psychologist works to train the parents in techniques for managing the conduct of their children. For the sticker chart there are three signs that can be placed on the chart in response to the child's behaviour: a star for good behaviour, a sad face for poor behaviour and a big cross through the square for the day for seriously problematic behaviour. For the time out procedure the parents are introduced to the "once nicely, once firmly rule" where instructions or requests are to be made of the child, the first statement said 'nicely', the second 'firmly', and if the child does not stop after this then they are advised: "If he carries on you take him, with absolutely no discussion, no eye contact, nothing, into another room in the house, and you lave him there for three minutes".

The psychologist then goes away for a week during which time the parents "practice her behavioural techniques on their own" in the presence of the cameras. In the next section of the programme the parents are shown applying the sticker chart and time out - the older child is rewarded with stickers for good behaviour and gets sad faces and crosses for bad behaviour. Time out is demonstrated in an episode in which the younger child throws a tantrum because there are no chocolate ice creams and he is removed to another room after which he settles down, gets a cuddle and an ice cream.

After a week another training technique is introduced: "Tanya's back to give Jo hands on coaching. She's going to teach Jo how to get better behaviour from her boys". The psychologist sits in the house while the mother plays with the two older boys in the garden. The mother is fitted with an earpiece so that she can hear the psychologist who is also fitted with a headset and has a TV screen on which to view 
the parent and child interacting while not being in the scene herself. In this way the psychologist can give real time coaching in parenting skills. The key skills that the psychologist concentrates on are allowing the children to take the lead and set the agenda in play and for the parent to give positive feedback to the children as they play together.

At this point in the narrative structure of the programme we have reached the point of resolution of the first disruption. However, there are further 'challenges' to be confronted and two further problems are dealt with: bedtime and shopping. In both cases remarkable changes in the children's behaviour re shown to result from the application of similar principles to those used to deal with disruptive behaviour. The splitting up of the problem behaviour into definable and workable behavioural issues reflects a common approach to therapeutic practice which isolates specific behaviours and provides cognitive behavioural solutions by changing the parents understanding of the targeted behaviour and uses behavioural techniques to initiate change.

In the final scene the parents reflect on the effects of adopting Tanya's strategies and rules: it is more fun to be with their children. As the mother puts it, "What I think has come to light from doing the programme and taking Tanya's advice and everything, is that it's parents behaviour and attitude towards the children that can make them better behaved. They haven't necessarily become any better behaved from doing this, we've just been able to manage what we like and what we don't like". The father is very positive also and the final scene is of the parents being able to go out together for the first time in ages in the evening to play bowls.

\section{Analysis and Conclusions}

Little Angels is a complex production that combines a number of elements of documentary making with a lifestyle transformation reality TV format. The programme presents a narrative of transformation through the editing together of a 
variety of live shot material and talking heads with an accompanying voice over narration. The pace of the programme is unremitting - voice over narrative sections of the programme over fast cutting excerpts of live shot material interspersed with interview material with the parents and shots of the psychologist working with the parents.

The programme is tightly structured as a narrative with an initial state of disruption which is confronted with the help of an external heroic figure (the psychologist) who deploys her special skills to enable the participants (the parents) to overcome their problems. As in many hero narratives a series of three challenges are presented and the common focus on the participants going on a journey of self discovery under the guidance of a guru/teacher is played out. the disruptions consist of problems that parents have with young children such as disruptive behaviour, not sleeping, tantrums.

The moment of reflection, where the psychologist sits down with the parents in front of the camera to reflect on their own and their children's behaviour is a key moment in the programme. It hinges the narrative since it is based on the analysis of the live shot material collected from the cameras in the household. It provides an analysis of that behaviour, it humiliates the parents to some degree by publicly exposing their doubts and limitations and it affords the introduction of a psychological account of the link between parenting and children's behaviour and allows the development of the plans to be enacted by the parents in the rest of the programme. The shift in the narrative of transformation from a focus on the children's behaviour to the conduct of the parents is also accomplished through this scene.

Another important element of the show's rationale? comes to the fore at this critical moment. These scenes are often also moments of public emotional vulnerability for the parents as they experience the shame of having their behaviour dissected and their inadequacies pointed out. The technique that the psychologist deploys is one derived from social skills training and often deployed in clinical contexts; watching video's of ones performance makes visible tacit aspects of conduct and the subject becomes an observer of their own behaviour in a very literal sense. This scene is also important for licensing the role of the psychologist in a particular therapeutic role. The therapeutic intervention takes a very particular form combining elements of clinical interviewing, lectures, life coaching and role play. This presents an interesting contrast to documentary style programming in which the therapy would 
be portrayed as a process going on off air which is recorded and reflected on at key moments. In contrast, in Little Angels, there is little reference to work between the psychologist and the parents behind the scenes. Instead the work is presented as done in front of the cameras (although edited to be sure). This also indicates the centrality of performance in constituting the transformation in the lives of the parents and the children in these programmes. There is relatively little verbal reflection on the programme which mainly consists of live shot material of parent-child interaction.

Although the expert on the programme is a psychologist, the use of psychological vocabulary is limited and effort appears to be made by the psychologist to talk in lay terms about and to the parents concerning their behaviour and the children's. The words that the psychologist uses — 'reward', 'routine', 'time out'—are all examples of terms that are widely disseminated in vernacular discourse. The adoption of psychological discourse is also conducted as a performance played out in the interaction between the psychologist and the parents. Only briefly does the psychologist directly address the audience at home and this is during the part of the programme when she is communicating with the parents over close circuit TV and audio link. In the sections of the programmes where the psychologist provides support and commentary to the parents expertise is adapted to providing advice, encouraging reflection, coaching in parenting skills and emotionally supporting the parents. In other words the psychologist is present mainly in her therapeutic role and the knowledge that is made public is given in the form of a performance of the therapeutic relationship rather than an expert account of the problems between parents and children. A performance of parenting, loosely informed by psychological principles is co-enacted by the therapist and the parent and both adjust and orient towards the child in ways that are attuned to bringing about specific changes in the child's behaviour.

In relation to the sociological theories of governmentality and reflexive modernity it is clear that both theories provide illuminating but partial ways of analysing and theorizing both the structure and content of such programming and the broader social significance of the increasing visibility of individuals in contemporary society. Governmentality theory draws our attention to the role of psychological discourse, the use of techniques of training and self control and the importance of surveillance technology. Reflexive modernity theory provides an emphasis on the transformation of expertise as self-help, the narrative dimension of self-transformation 
and the role of the media as an institution of civil society. The deployment of psychological discourse, the enrolment of the parents through a training regime into an ethic of self-reflection are recognizable representations of governmentality. However, The ways in which psychological expertise is adapted to the practical concerns of the parents and the narrative conventions of the makeover format aimed at the reflection of the audience at home can be seen as a contemporary form of selfhelp supporting joint parenting roles for young professionals.

Finally, what does this mean for the public service ethic of the BBC? Something intriguing is happening in relation to the blurring of the boundaries between factual broadcasting and entertainment, the shifting nature of expertise and the proliferation of the representation of everyday life problems (Bondebjerg, 2002). Public service television now appears to combine elements of surveillance with selfhelp resources as part of the mediation of civil society. The question remains whether the best interpretation of such programmes is that they provide a way in which participants and audiences internalise a normative psychological vocabulary under conditions of surveillance leading to docile subjects or whether the programmes represent an institutionalization of civil society that pragmatically facilitates self help in parents.

\section{References}

Andrejevic, M. (2004). Reality TV: the work of being watched, Rowman \& Littlefield. A. Barry, T. Osborne, N. Rose (1996)(Eds.) Foucault and Political Reason: liberalism, neo-liberalism and rationalities of government. London: UCL Press.

Beck, U. and Beck-Gernsheim, (2002). Individualization. London: Sage.

Bondebjerg, I. (2002). The mediation of everydaylife: genre, discourse and spectacle in reality TV. In A. Jerslev (Ed.) Realism and 'Reality' in Film and Media. Copenhagen: Museum Tusculanum Press. 159-92.

Brunsdon, C. (2003) Lifestyling Britain: The 8-9 slot on British television. International Journal of Cultural Studies, 6(1), 5-23. 
Dean, M. (1999) Governmentality: Power and rule in modern society. London: Sage.

Dovey, J. (2000). Freakshow. London: Polity Press.

Furedi, F. (2004). Therapy Culture: Cultivating Vulnerability in an Uncertain Age. London: Routledge.

Giddens, A. (1991). Modernity and Self Identity. Cambridge: Polity Press.

Grindstaff, L. (2002). The Money Shot: Trash, Class, and the making of TV Talk Shows. Chicago: Chicago University Press.

Hill, A. (2005). Reality TV: Audiences and popular factual television. London: Routledge.

Hill, A. (2007) Restyling Factual TV: audiences and news, documentary and reality genres. London: Routledge.

Illouz, E. (2003) Oprah Winfrey and the Glamour of Misery: An Essay on Popular Culture. New York: Columbia University Press.

James, A. Jenks, C. and Prout, A. (1998). Theorizing Childhood. Cambridge: Polity Press.

Lewis, T. (2008) Smart Living: Lifestyle Media and Popular Expertise (New York, Peter Lang).

Livingstone, S. and Lunt, P (1994) Talk on Television: Audience participation and public debate. London: Routledge.

Lunt, P. and Livingstone, S. (1992) Mass Consumption and Personal Identity. Buckingham: Open University Press.

Lunt, P. and P. Stenner (2005) 'The Jerry Springer Show as an emotional public sphere', Media, Culture \& Society 27(1): 59-8.

Moseley, R. (2000). "Makeover takeover on British television." Screen 41(3): 299314. 
Ouellette, L and Hay, J. (2008) Better Living through Reality TV: Television and Post-welfare Citizenship. Blackwell, USA.

Palmer, G. (2003). Discipline and liberty : television and governance. Manchester, UK ; New York.

Parsons, T. (1951). The Social System. London: Routledge, Keegan \& Paul.

Philips, D. (2005). Transformation Scenes: The television interior makeover. International Journal of Cultural Studies, 8(2), 213-229.

Rose, N. (1989). Governing the soul: the shaping of the private self, Routledge.

Taylor, L. (2002). "From Ways of Life to Lifestyle: The 'Ordinari-ization' of British Gardening Lifestyle Television." European Journal of Communication 17(4): 479-493. 